\title{
Oxiziridinium Salts as Hydrophobic Epoxidizing Reagents: Remarkable Hydrophobically-Directed Selectivity in Olefin Epoxidation
}

\author{
Mark Biscoe and Ronald Breslow*
}

\section{Supporting Information}

\section{General Information:}

a. Chemicals: THF, $\mathrm{CH}_{2} \mathrm{Cl}_{2}$, DMF, and ether were dried through columns of activated molecular sieves. Other solvents, inorganic salts, and organic reagents were purchased from commercial sources and used without further purification unless otherwise mentioned.

b. Chromatography: Merck pre-coated $0.25 \mathrm{~mm}$ silica plates containing a $254 \mathrm{~nm}$ fluorescence indicator were used for analytical thin-layer chromatography. Flash chromatography was performed on 230-400 mesh silica (Silica Gel 60) from EM Science.

c. Spectroscopy: NMR spectra were obtained on a Bruker DPX 300, 400, or $500 \mathrm{MHz}$ spectrometer. APCI MS spectra were taken on a Nermag R-10-10 instrument. FAB MS spectra were taken on a JEOL JMS-DX-303 HF instrument using either glycerol or p-nitrobenzyl alcohol as matrices. All data processing was performed using Bruker XMass/XTOF V 5.0.2.

\section{Procedures for Competition Reactions:}

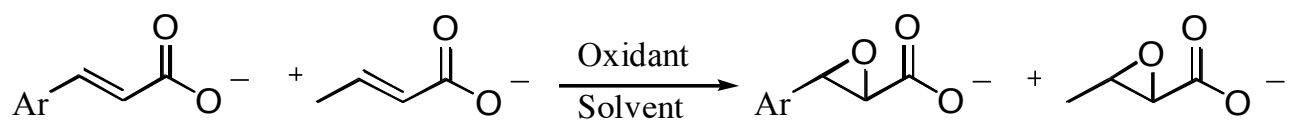

\section{Ar $=$ Phenyl:}

When the oxidant was a peracid or dimethyldioxirane (DMDO), reactions were conducted at a substrate concentration of $50 \mathrm{mM}$ in $200 \mathrm{mM} \mathrm{NaHCO} / \mathrm{D}_{2} \mathrm{O}$. When the oxidant was highly selective oxaziridinium 6 or 7, $10 \mathrm{mM}$ cinnamic acid and $100 \mathrm{mM}$ crotonic acid in $200 \mathrm{mM} \mathrm{NaHCO} / \mathrm{D}_{2} \mathrm{O}$ were used in order to make the ${ }^{1} \mathrm{H}$ NMR signals of epoxycrotonate more easily integrated. The integrals of epoxycrotonate signals were then divided by ten. For ${ }^{1} \mathrm{H}$ NMR analysis of product ratios, either of the epoxide proton signals of epoxycinnamate $(\delta 4.00, \mathrm{~d}, 1 \mathrm{H}, \mathrm{J}=2.2 \mathrm{~Hz} ; \delta 3.55, \mathrm{~d}, 1 \mathrm{H}, \mathrm{J}=2.2 \mathrm{~Hz})$ and epoxycrotonate $(\delta 3.20$, $\mathrm{d}, 1 \mathrm{H}, \mathrm{J}=2.3 \mathrm{~Hz} ; \delta 3.15$, qd, $1 \mathrm{H}, \mathrm{J}=5.2 \mathrm{~Hz}, 2.3 \mathrm{~Hz}$ ) could be used. The signal for the methyl protons of epoxycrotonate $(\delta 1.31, \mathrm{~d}, 3 \mathrm{H}, \mathrm{J}=5.2 \mathrm{~Hz})$ could also be used. For competition reactions in 1:1 (v/v) $\mathrm{D}_{2} \mathrm{O}$ : $i \mathrm{PrOD}, 0.25 \mathrm{ml} i$ PrOD was combined with $0.25 \mathrm{ml}$ of the $\mathrm{NaHCO}_{3} / \mathrm{D}_{2} \mathrm{O}$ substrate solution. The HOD peak in the ${ }^{1} \mathrm{H}$ NMR spectrum was calibrated to $\delta 4.80$. The signals of epoxycinnamate are located at $\delta 4.08(1 \mathrm{H})$, and $\delta 3.52(1 \mathrm{H})$. The signals of epoxycrotonate are located at $\delta 3.19-3.23(2 \mathrm{H})$ and $\delta 1.44$ $(3 \mathrm{H})$. All chemical shifts vary slightly depending on the exact $\mathrm{pH}$ of the solution examined.

\section{$\mathrm{Ar}=4-\mathrm{CF}_{3}-$ Phenyl:}

When the oxidant was a peracid or dimethyldioxirane (DMDO), reactions were conducted at a substrate concentration of $10 \mathrm{mM}$ in $250 \mathrm{mM} \mathrm{NaHCO} / \mathrm{D}_{2} \mathrm{O}$. When the oxidant was highly selective oxaziridinium 6 or 7, $10 \mathrm{mM}$ 4-trifluoromethylcinnamic acid and $50 \mathrm{mM}$ crotonic acid in $350 \mathrm{mM} \mathrm{NaHCO} / \mathrm{D}_{2} \mathrm{O}$ were used. The integrals of epoxycrotonate signals were then divided by five. For ${ }^{1} \mathrm{H}$ NMR analysis of product ratios, either of the epoxide proton signals of epoxy-4-trifluoromethylcinnamate $(\delta 4.02, \mathrm{~d}, 1 \mathrm{H}, \mathrm{J}=2.0 \mathrm{~Hz} ; \delta 3.50$, $\mathrm{d}, 1 \mathrm{H}, \mathrm{J}=2.0 \mathrm{~Hz}$ ) could be used. For competition reactions in $1: 1(\mathrm{v} / \mathrm{v}) \mathrm{D}_{2} \mathrm{O}: i \operatorname{PrOD}, 0.25 \mathrm{ml} i \operatorname{PrOD}$ was combined with $0.25 \mathrm{ml}$ of the $\mathrm{NaHCO}_{3} / \mathrm{D}_{2} \mathrm{O}$ substrate solution. The HOD peak in the ${ }^{1} \mathrm{H}$ NMR spectrum 
was calibrated to $\delta 4.80$. The signals of epoxy-4-trifluoromethylcinnamate are located $\delta 4.13(1 \mathrm{H})$, and $\delta 3.45(1 \mathrm{H})$. All chemical shifts vary slightly depending on the exact $\mathrm{pH}$ of the solution examined.

\section{Ar = 2-Naphthyl:}

When the oxidant was MMPP or dimethyldioxirane (DMDO), reactions were conducted at a substrate concentration of $5 \mathrm{mM}$ in $250 \mathrm{mM} \mathrm{NaHCO} / \mathrm{D}_{2} \mathrm{O}$. When the oxidant was highly selective oxaziridinium 6 or 7, $5 \mathrm{mM}$ 3-(2-naphthyl)acrylic acid and $75 \mathrm{mM}$ crotonic acid in $450 \mathrm{mM} \mathrm{NaHCO} / \mathrm{D}_{2} \mathrm{O}$ were used. The integrals of epoxycrotonate signals were then divided by fifteen. For ${ }^{1} \mathrm{H}$ NMR analysis of product ratios, either of the epoxide proton signals of epoxy-3-(2-naphthyl)acrylate $(\delta 4.11, \mathrm{~d}, 1 \mathrm{H}, \mathrm{J}=2.2 \mathrm{~Hz} ; \delta 3.64, \mathrm{~d}, 1 \mathrm{H}$, $\mathrm{J}=2.2 \mathrm{~Hz}$ ) could be used. When the oxidant was PFPP or PAA, the tetramethylammonium salts of crotonic acid and 3-(2-naphthyl)acrylic acid were employed in order to prevent substrate precipitation upon addition of oxidant. These reactions were conducted at a substrate concentration of $15 \mathrm{mM}$ in $\mathrm{D}_{2} \mathrm{O}$ w/o $\mathrm{NaHCO}_{3}$. The signals of epoxy-3-(2-naphthyl)acrylate are located $\delta 4.08(1 \mathrm{H})$, and $\delta 3.61(1 \mathrm{H})$. If some precipitation was observed, addition of a small amount of $\mathrm{Me}_{4} \mathrm{NHCO}_{3}{ }^{1}$ produced homogeneity. Use of the tetramethylammonium salt of PFPP was also effective in preventing precipitation. Ratios were reproduced through each of these methods. For competition reactions in 1:1 (v/v) $\mathrm{D}_{2} \mathrm{O}: i \operatorname{PrOD}, 0.25 \mathrm{ml}$ of $i$ PrOD was combined with $0.25 \mathrm{ml}$ the above tetramethylammonium substrate solution. The HOD peak in the ${ }^{1} \mathrm{H}$ NMR spectrum was calibrated to $\delta 4.80$. The signals of epoxy-3-(2-naphthyl)acrylate are located $\delta 4.13(1 \mathrm{H})$, and $\delta 3.52(1 \mathrm{H})$. All chemical shifts vary slightly depending on the exact $\mathrm{pH}$ of the solution examined.

\section{3,4-Dihydro-naphthylene-2-carboxylic acid (3):}

When the oxidant was a peracid or dimethyldioxirane (DMDO), reactions were conducted at a substrate concentration of $20 \mathrm{mM}$ in $150 \mathrm{mM} \mathrm{NaHCO} / \mathrm{D}_{2} \mathrm{O}$. When the oxidant was highly selective oxaziridinium 6 or $7,15 \mathrm{mM} 3$ and $300 \mathrm{mM}$ crotonic acid in $550 \mathrm{mM} \mathrm{NaHCO} / \mathrm{D}_{2} \mathrm{O}$ were used. The integrals for the epoxycrotonate signals were then divided by twenty. For ${ }^{1} \mathrm{H}$ NMR analysis of product ratios, the epoxide proton signal of the epoxy-3,4-dihydronaphthylene-2-carboxylate $(\delta 3.99, \mathrm{~s}, 1 \mathrm{H})$ was used. For competition reactions in 1:1 (v/v) $\mathrm{D}_{2} \mathrm{O}: i \mathrm{PrOD}, 0.25 \mathrm{ml} i \operatorname{PrOD}$ was combined with $0.25 \mathrm{ml}$ of the $\mathrm{NaHCO}_{3} / \mathrm{D}_{2} \mathrm{O}$ substrate solution. The HOD peak in the ${ }^{1} \mathrm{H}$ NMR spectrum was calibrated to $\delta 4.80$. The epoxide proton signal of epoxy-3,4-dihydronaphthylene-2-carboxylate is located at $\delta 4.07(\mathrm{~s}, 1 \mathrm{H})$. All chemical shifts vary slightly depending on the exact $\mathrm{pH}$ of the solution examined.

\section{Procedure for Catalytic Epoxidations Using Iminium Salts:}

The reactions were conducted at a substrate concentration ( $\mathrm{NMe}_{4}$ salts) of $20 \mathrm{mM}$ and an iminium catalyst concentration of $1 \mathrm{mM}$ in $\mathrm{D}_{2} \mathrm{O}$. A $150 \mathrm{mM}$ oxone solution in $\mathrm{D}_{2} \mathrm{O}$ was prepared and neutralized using $\mathrm{Me}_{4} \mathrm{NHCO}_{3}{ }^{1}$. A droplet of the oxone solution was added to $0.5 \mathrm{ml}$ of substrate/iminium solution to effect less than $10 \%$ conversion of substrates. The resulting product ratio was analyzed by ${ }^{1} \mathrm{H}$ NMR spectroscopy in an analogous fashion as described for the competition reactions in which stoichiometric oxidants were employed. Once a product distribution reflecting initial rates was obtained, excess oxone solution was added. The catalytic turnover number was determined through comparison of the epoxidized products to the non-epoxidized products in the ${ }^{1} \mathrm{H}$ NMR spectrum.

\section{Synthesis:}

Syntheses of samples of known epoxides were conducted using a previously reported procedure. ${ }^{2}$ The Na salts of these $\alpha, \beta$-epoxy acids were used for spectral comparison to in situ epoxidized substrates in competition reactions.

An aqueous solution of peracetic acid (PAA) was prepared using a known procedure. ${ }^{3}$

\footnotetext{
${ }^{1}$ Tong, K.-H.; Wong, K.-Y.; Chan, T. H. Org. Lett. 2003, 5, 3423-3425.

2 Yang, D.; Wong, M.-K.; Yip, Y.-C. J. Org. Chem. 1995, 60, 3887-3889.

${ }^{3}$ Owen, T. C.; Gladys, C. L.; Field, L. J. Chem. Soc. 1962, 501-507.
} 
<smiles>O=C(O)C1=Cc2ccccc2CC1</smiles>

3,4-Dihydro-naphthylene-2-carboxylic acid methyl ester ${ }^{4}(3.2 \mathrm{~g}, 17 \mathrm{mmol})$ was dissolved in $90 \mathrm{ml} \mathrm{THF}, 30$ $\mathrm{ml} \mathrm{H}_{2} \mathrm{O}$, and $30 \mathrm{ml} \mathrm{MeOH}$. $\mathrm{LiOH}-\mathrm{H}_{2} \mathrm{O}(3.57 \mathrm{~g}, 85 \mathrm{mmol})$ was added to the reaction mixture at room temperature and stirred overnight. The reaction was acidified with $4 \mathrm{M} \mathrm{HCl}$ and extracted twice with $\mathrm{CH}_{2} \mathrm{Cl}_{2}$. The combined $\mathrm{CH}_{2} \mathrm{Cl}_{2}$ layers were washed twice with $100 \mathrm{ml} 15 \% \mathrm{NaOH}$. The combined aqueous layers were then acidified with $4 \mathrm{M} \mathrm{HCl}$. The white solid that forms was extracted with $\mathrm{CH}_{2} \mathrm{Cl}_{2}$, which was then dried over $\mathrm{MgSO}_{4} .1 .96 \mathrm{~g}$ (66\% yield) of a pure pale yellow solid was isolated after removal of solvent. ${ }^{1} \mathrm{H}$ NMR (400 Mhz, DMSO-d $\left.{ }_{6}\right): \delta 12.43(\mathrm{~s}, 1 \mathrm{H}), 7.47(\mathrm{~s}, 1 \mathrm{H}), 7.20-7.33(\mathrm{~m}, 4 \mathrm{H}), 2.81(\mathrm{t}$, $2 \mathrm{H}, \mathrm{J}=8.1 \mathrm{~Hz}), 2.47$ (td, 2H, J=8.1, 1.6 Hz). ${ }^{13} \mathrm{C}$ NMR (100 Mhz, DMSO-d $\left.{ }_{6}\right): \delta 167.6,136.1$, 135.0, 131.9, 129.6, 129.0, 128.0, 127.2, 126.4, 27.0, 22.0. APCI+ MS: $174.8(\mathrm{M}+1)^{+}$.

\section{Epoxy-3,4-Dihydro-naphthylene-2-carboxylic acid:}

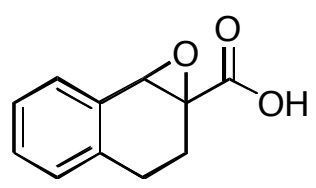

3,4-Dihydro-naphthylene-2-carboxylic acid $(0.1 \mathrm{~g}, 0.57 \mathrm{mmol})$ was added to $10 \mathrm{ml}$ acetone and $10 \mathrm{ml}_{2} \mathrm{O}$. A solution of $\mathrm{NaHCO}_{3}(0.40 \mathrm{~g}, 4.8 \mathrm{mmol})$ and oxone $(0.53 \mathrm{~g}, 0.86 \mathrm{mmol})$ in $15 \mathrm{ml} \mathrm{H}_{2} \mathrm{O}$ was added dropwise to the stirred reaction mixture at room temperature. After 90 minutes, the reaction mixture was poured into a separatory funnel containing $25 \mathrm{ml}$ ice water and was made acidic through dropwise addition of ice cold $0.5 \mathrm{~N} \mathrm{HCl}$. The aqueous layer was extracted with EtOAc, which was dried over $\mathrm{Na}_{2} \mathrm{SO}_{4}$ and rotovapped to afford $0.076 \mathrm{~g}$ (70\% yield) of a white powder. ${ }^{1} \mathrm{H}$ NMR (500 Mhz, CDCl3): $\delta 7.42$ (d, $1 \mathrm{H}, \mathrm{J}=7.4 \mathrm{~Hz}$ ), 7.32 (t, 1H, J=7.4 Hz), 7.24 (t, 1H, J=7.0 Hz), 7.14 (d, 1H, J=7.4 Hz), 4.15 (s, 1H), 2.82 (td, 1H, J=14.8, $6.3 \mathrm{~Hz}$ ), 2.67 (dd, 1H, J=15.3, 5.1 Hz), 2.55 (dd, 1H, J=14.7, 5.1 Hz), 2.28 (td, 1H, J=14.4, 5.5 Hz). ${ }^{13} \mathrm{C}$ NMR (100 Mhz, CDCl3): $\delta 174.9,136.6,130.0,129.7,129.4$, $128.5,126.5,60.5,58.8,25.2,21.9$. APCI+ MS: $190.8(\mathrm{M}+1)^{+}$.

\section{Perfluoromonoperoxyphthalate, Na salt:}<smiles>O=C(OO)c1c(F)c(F)c(F)c(F)c1C(=O)O[Na]</smiles>

This procedure is based upon a reported procedure for the preparation of monoperoxyphthalates. ${ }^{5} \mathrm{~A}$ solution of $\mathrm{Na}_{2} \mathrm{CO}_{3}(0.5 \mathrm{~g}, 4.6 \mathrm{mmol})$ in $25 \mathrm{ml} \mathrm{H}_{2} \mathrm{O}$ was cooled to $0^{\circ} \mathrm{C} .35 \% \mathrm{H}_{2} \mathrm{O}_{2}(1 \mathrm{ml}, 12 \mathrm{mmol})$ was added, followed by tetrafluorophthalic anhydride $(0.5 \mathrm{~g}, 2.3 \mathrm{mmol})$. After having stirred for 1 hour at $\mathrm{O}^{\circ} \mathrm{C}$, the reaction solution was poured into a separatory funnel containing $50 \mathrm{ml}$ ether. Ice cold $\mathrm{H}_{2} \mathrm{SO}_{4}(40 \%)$ was added slowly dropwise until the aqueous layer was acidic. The aqueous layer was extracted twice with

\footnotetext{
${ }^{4}$ Vebrel, J.; Carrio, R. Bull. Soc. Chim. Fr. 1982, 3-4 part 2, 116-124.

5 Payne, G. B. Org. Syn. 1962, 42, 77-78.
} 
ether. The combined ether layers were washed with $\mathrm{H}_{2} \mathrm{O}$ and dried over $\mathrm{MgSO}_{4}$. After rotovapping, the cloudy residue was dissolved in $25 \mathrm{ml} \mathrm{H}_{2} \mathrm{O}$ and neutralized with $\mathrm{NaHCO}_{3}$ (For the $\mathrm{NMe}_{4}$ salt, the aqueous solution was neutralized with $\mathrm{NMe}_{4} \mathrm{OH}$ ). $200 \mathrm{mg}$ of a fluffy white solid was isolated after lyophilization. 1:1 mixture of perfluoromonoperoxyphthalate and perfluorophthalate. The salt was stored in a freezer. ${ }^{19} \mathrm{~F}$ NMR (282 Mhz, $\left.\mathrm{D}_{2} \mathrm{O}\right): \delta$-136.19 (m, 1F), -140.73 (m, 1F), -146.75 (td, 1F, J=21.2, 7.3 Hz), 153.30 (t, 1F, J=19.0 Hz). 